\title{
Self-Segregation or Deliberation? Blog Readership, Participation, and Polarization in American Politics
}

\author{
Eric Lawrence, John Sides, and Henry Farrell
}

\begin{abstract}
Political scientists and political theorists debate the relationship between participation and deliberation among citizens with different political viewpoints. Blogs provide an important testing ground for their claims. We examine deliberation, polarization, and political participation among blog readers. We find that blog readers gravitate toward blogs that accord with their political beliefs. Few read blogs on both the left and right of the ideological spectrum. Furthermore, those who read left-wing blogs and those who read right-wing blogs are ideologically far apart. Blog readers are more polarized than either non-blog-readers or consumers of various television news programs, and roughly as polarized as US senators. Blog readers also participate more in politics than nonblog readers. Readers of blogs of different ideological dispositions do not participate less than those who read only blogs of one ideological disposition. Instead, readers of both left- and right-wing blogs and readers of exclusively leftwing blogs participate at similar levels, and both participate more than readers of exclusively right-wing blogs. This may reflect social movement-building efforts by left-wing bloggers.
\end{abstract}

W hat is the relationship between blogs-regularly updated web pages consisting of posts in reverse chronological order — and political behavior? This has been the topic of much debate among commentators and, increasingly, political scientists. ${ }^{2}$ These debates have focused on two key questions. First, do political blogsblogs that focus on the daily ebb and flow of national, state, and local politics - facilitate deliberation? Some political theorists ${ }^{3}$ idealize deliberation among individuals with diverse perspectives. They claim that deliberation may help individuals refine their own opinions, develop greater tolerance for different opinions, and perhaps identify common ends and means. Deliberation theorists often deplore the perceived polarization of American politics, which they

Eric D. Lawrence is Assistant Professor of Political Science at George Washington University edl@gwu.edu. John Sides is Assistant Professor of Political Science at George Washington University jsides@gwu.edu. Henry Farrell is Assistant Professor in the Department of Political Science and Elliott School of International Affairs at George Washington University farrellh@gwu.edu. ${ }^{1}$ We wish to thank Yochai Benkler, Josh Cohen, Steven Berlin Johnson, Kieran Healy, Marc Lynch, Cosma Shalizi, Lee Sigelman and Cass Sunstein, as well as the readers of Crooked Timber (http:// www.crookedtimber.org) and The Monkey Cage (http:// www.themonkeycage.org) for their comments on earlier versions of this article, and Davy Banks and Adrian Johnston for research assistance. believe leads to hardened opinions, diminishing tolerance for opposing points of view, and increasing dissensus, ${ }^{4}$ although some $e^{5}$ believe that partisan organizations can have beneficial deliberative consequences.

Second, do blogs stimulate political participation? High levels of political participation are routinely lauded as a vital element of healthy democracy. ${ }^{6}$ As Macedo et al. ${ }^{7}$ contend, increased participation and civic engagement are likely to lead to more responsive politics, more legitimate politics, and improvements in the quality of citizens' lives.

The problem, however, is that deliberation and participation may be at odds. Mutz ${ }^{8}$ finds that exposure to competing points of view in one's personal network is associated with increased tolerance for opposing views but decreased levels of political participation. This poses a "disturbing dilemma" for notions of citizenship: we would like citizens both to be enthusiastic participants in politics and to respect diverse perspectives. Mutz suggests that there may be no good way to accomplish both ends.

This dilemma is more acute in this age of expanding media choice, which, as Prior ${ }^{9}$ argues, affects both political polarization and participation. Individuals with little interest in politics can more easily avoid political news and are therefore less politically knowledgeable and less likely to participate in politics. In contrast, those interested in politics will consume news and become more politically informed by doing so. Politics as a whole becomes more polarized because those with little interest in politics-those who are now becoming less and less involved in politics-tend to be less partisan and more 
ideologically moderate. If this polarization is associated with a lack of dialogue between opposing viewpoints, then there will be little potential for fruitful deliberation.

Evidence drawn from blogs enables us to better understand the relationships among media choice, deliberation, polarization, and participation. The importance of blogs derives in part from how they innovate on traditional media. Innovations in media technology are often neglected within political science and this neglect limits our understanding of politics: "[i]f changes in communications technology are consequential, neglecting them in our theories of the political process is a consequential mistake". ${ }^{10}$ Blogs may be just such a consequential technology. Although blogs that set out political points of view probably constitute a small minority within the "blogosphere" - the universe of blogsthey have attracted large readerships in the United States and elsewhere, as well as considerable media attention.

Unlike traditional or "mainstream" media outlets, blogs provide non-elites with an easy and relatively inexpensive way to set out their opinions. The sheer proliferation of political blogs has created greater variety in their political agendas and ideologies-liberal, conservative, centrist, libertarian, and so on - than there is in the traditional media, which either seek to present themselves as professionally objective or adhere to one of a few wellestablished models of partisan discourse (e.g., the bellicose ideologue-as-host or the "Crossfire" format). Blogs are also a fundamentally interactive medium. Many blogs allow readers to leave comments responding to the blog's author and to each other, with the author sometimes replying. Even blogs that do not allow comments create ongoing conversations with other blogs, as authors link and respond to one another, thereby potentially exposing their respective readers to more voices and creating complex networks of idea diffusion and percolation. To investigate blog readership, we draw on comprehensive survey data to link specialized academic debates over blogs with broader theoretical debates among political scientists. Although our data cannot clearly demonstrate any causal relationships, they can be used to evaluate extant causal arguments. We would expect specific patterns of association to emerge given the arguments of Mutz, Prior, and others. By looking for these patterns, we test the applicability of these arguments to this new medium.

Our primary research questions center on the level of polarization and participation among blog readers. To determine the extent of polarization, we first ask whether political blog readers tend to read left-wing blogs, right-wing blogs, or both. We then map the ideological contours of each group, comparing polarization among blog readers to that among consumers of traditional media. We also investigate political participation among blog readers. Are political blog readers more participatory, on average? Does their level of participation depend on which blogs they read-with those exposed to competing points of view within the blogosphere less likely to participate than those exposed only to one side? Answers to these questions will help us not only to characterize the media habits of citizens in an era of expanding choice, but also to appraise the merits and the demerits of blogs as arenas for deliberation and catalysts for participation.

\section{The Behavior of Blog Authors and Blog Readers \\ Blog Authors}

The political consequences of blogs depend on two sets of actors: authors and readers. Blog authors have considerable discretion over how they structure their blogs. They control the content they themselves produce-which reflects their own political opinions - and also which other viewpoints are presented. As bloggers engage with each other and with other sources of information on the Internet, they create hyperlinks that may lead, for example, to posts written by another blogger with whom they agree or disagree. ${ }^{11}$ These inter-blog networks have been examined in research on the distribution of links in the blogosphere. ${ }^{12}$

Most relevant for our purposes is research on ideological affinities in these networks. Two important studies of prominent political blogs conclude that bloggers exhibit homophily, the tendency to associate with others who are similar to them. ${ }^{13}$ Specifically, they are much more likely to link to bloggers sharing their ideological orientation than to bloggers on the other side of the political spectrum. ${ }^{14}$ Glance and Adamic find that only 15 per cent of links among 40 prominent political blogs moved from left-wing bloggers to right-wing bloggers, or vice-versa. Hargittai, Gallo, and Kane report similar findings from a more extended sample.

Such findings feed into broader debates over the normative benefits and drawbacks of online conversation, as well as ${ }^{15}$ the fears of some, notably Sunstein, ${ }^{16}$ that blogs do not engender conversations between people with differing political views. Instead, Sunstein argues, blogs reinforce readers' and authors' ideological perspectives instead of challenging them, and thereby lead to increased political polarization over time. Habermas ${ }^{17}$ is similarly pessimistic, suggesting that the "horizontal and informal networking of communication [associated with the Internet] undermines the achievements [Errungenschaften] of traditional publics" in democratic regimes (our translation). More specifically, he claims ${ }^{18}$ that the Internet tends to fragment debate, giving rise to a "huge number of isolated issue publics." For Habermas, bloggers are only valuable to public debate insofar as they serve a "parasitical" function of criticizing and correcting the mainstream press. ${ }^{19}$

Others, such as Benkler ${ }^{20}$ and Woodly, ${ }^{21}$ disagree and argue that blogs empower the public and enhance deliberative democracy by making it easier to argue and to 
engage with others. Both Benkler and Woodly acknowledge homophily among bloggers, but note that bloggers do indeed engage the views of those with dissimilar political beliefs. Benkler and Woodly can also find some comfort in existing research findings. Although Hargittai et al. find infrequent links between left-wing and right-wing bloggers, they show that many of the links that do exist involve substantive argument and conversation. Furthermore, they find no evidence that insularity is increasing over time, as Sunstein and others might predict.

\section{Blog Readers and Political Polarization}

What about the choices of blog readers? These choices not only affect the content of blogs themselves, primarily via readers' comments, but also provide evidence about whether blogs are likely to foster deliberation or merely reinforce existing beliefs. Despite much political science research into relevant individual-level political behavior-with regard to interpersonal and media communication, political knowledge, polarization, and participation ${ }^{22}$ - no one has yet applied this research to political blogs. ${ }^{23}$

The best way to understand blog readers' choices is to consider blogs as providing political information, thus allowing us to borrow from existing accounts of how citizens acquire political information. One such account is that of Downs, ${ }^{24}$ who distinguished between "accidental" and "sought-for" information. ${ }^{25}$ Accidental political information is encountered inadvertently, as when a person watching "American Idol" sees a political advertisement during a commercial break. "Sought-for" information entails motivation: citizens must expend more effort to acquire it than they do when they acquire information accidentally.

Blogs typically provide sought-for, rather than accidental, information. Blog readers intentionally visit their preferred blog or blogs, and visit non-preferred blogs only when they click on links they have encountered elsewhere. If political blogs provide sought-for information, blog readers (of whatever ideological stripe) will be motivated to find political information. In Zaller's ${ }^{26}$ terminology, blog readers are highly "politically aware." In fact, they are likely more politically aware than are consumers of political information in the mainstream media. The audience for blogs is much smaller and more selective than that of mainstream news outlets, as individuals still face a higher search cost if they want to find political blogs than if they want to find news shows or specialized cable news channels. Thus, blogs exemplify the broader consequences of media fragmentation, ${ }^{27}$ in that they further demarcate a boundary between those who seek political information and those who do not.

What about the specific blogs people choose to read, and how those blogs conform to or deviate from people's own political opinions? Downs ${ }^{28}$ argued that a rational individual should seek sources of information that share his or her viewpoints:
When citizens rely on others to report events to them, rationality decrees that they select those reporters who provide them with versions of events that closely approximate the versions they would formulate themselves were they expert on-the-spot witnesses. To accomplish this, they must choose reporters whose selection principles are as nearly identical with their own as possible.

Blogs function much as "reporters" in this way: they select, aggregate, interpret, and sometimes independently produce information. They gather news from the mainstream media and highlight key stories and events; they provide commentary, often ideological or partisan, that helps readers understand these stories and events; and they themselves generate stories, much as mainstream news outlets do, by emphasizing events ignored by those outlets and even by undertaking their own reporting. ${ }^{29}$ They thus serve as extra eyes and ears for their readers. Most political blog readers no doubt consume information from other sources, but they also look to blogs to assist in this process.

Blog readers are thus likely to choose blogs whose authors have similar criteria for what is important and a similar interpretative lens through which they understand events and issues. In part, this tendency derives from blog readers' heightened level of political interest and awareness. Zaller ${ }^{30}$ shows that the politically aware have a larger number of stored ideas about political issues and objects, a more consistent or homogeneous set of ideas, and a greater resistance to attitude change. Each of these features suggests that blog readers have relatively crystallized, as opposed to ambivalent or malleable, attitudes.

As a consequence, when blog readers seek and process information, they are likely to be driven by "motivational" goals: ${ }^{31}$ they seek and engage information in ways that reaffirm their existing opinions. Motivated reasoning thereby entails selective exposure: people seek out arguments with which they already agree or are likely to agree. Lodge and Taber, ${ }^{32}$ describing their prior research, ${ }^{33}$ conclude:

As predicted by the selective exposure hypothesis, participantsespecially political sophisticates-were significantly more likely to read the arguments of sympathetic sources than to expose themselves to an opposing point of view. Moreover, they polarized as a result of their selective exposure: subjects who were most biased in their information search became more extreme in their attitudes, while subjects below the median in search bias did not polarize.

This tendency among "political sophisticates" is important, given that political blog readers themselves tend to be relatively sophisticated. Furthermore, Lodge and Taber's finding of polarization suggests that sympathetic arguments not only affirm prior views but also move them farther in the same direction, just as critics like Sunstein suspect that blogs do. Left- and right-leaning blogs therefore tend to attract those seeking kinship, not crossfire. And Prior's "escape" of moderates continues apace, as those 
with less interest in politics, who tend to be more moderate, largely avoid political blogs.

The online networks that blogs create are thus analogous to the personal networks within which people engage in political discussion. As Mutz ${ }^{34}$ demonstrates, these networks are also homophilous. People with similar political views flock together, a tendency heightened among the politically aware and facilitated by lifestyle enclaves and the World Wide Web:

As John Hlinko, founder of ActForLove.org, an Internet dating site for liberals put it, "Politics is a proxy for your basic values. This is what people care about. If you don't share the same core values as someone, it's going to be really tough for (a relationship) to take off." Similar Web sites such as Conservativematch.com, SingleRepublicans.com and LiberalHearts.com, also suggest that although looking for love may be a nonpartisan endeavor, for some politics serves as a useful shorthand. ${ }^{35}$

Individuals prefer social contexts populated by others who share their core political values and avoid social discourse with people who disagree with them profoundly over politics. This effect is driven in part by the informational motivations discussed above and in part by social dynamics; many people find it awkward and uncomfortable to debate others who do not share their core views. Ultimately, homophily within networks likely coincides with polarization - that is, the divergence of competing partisans or ideologues, such that individuals who initially leaned to the left find themselves moving farther left over time, and individuals who initially leaned to the right move farther right. Even if, as Mutz notes, it is difficult to ascertain the direction of causation-polarization may happen either because homogeneous networks produce movement towards the ideological poles, or because already-polarized people are more likely to self-select into homogeneous networks - the net effect in either case is that discourse on blogs falls well short of the deliberative ideal.

\section{Blog Readers and Political Participation}

Less clear is the relationship between blog readership and political participation. On the one hand, the composition of individuals' social networks may have significant consequences for participation. ${ }^{36}$ People who are exposed to arguments from those who disagree with them are more tolerant of others, but also less likely to engage in politics in a variety of ways. Mutz attributes this effect to two mechanisms. First, individuals exposed to contradictory information are less sure of their own attitudes and beliefs, and thus less likely to act on those beliefs. Second, individuals seek wherever possible to avoid social conflict with others in their network. This makes individuals in mixed political networks less likely to engage in political activity that might be viewed negatively by other network members. If Mutz's arguments can be extended to the blogosphere, then, ceteris paribus, indi- viduals exposed to competing points of view should be less likely to participate in politics than those who exclusively read left- or right-wing blogs.

On the other hand, as we hypothesized above, blog readers likely pay a lot of attention to politics and are quite politically informed. This in turn makes them especially likely to participate in politics. ${ }^{37}$ Thus, an alternative expectation is that blog readers of all stripes will be equally, and highly, participatory. If so, those exposed to competing viewpoints will be no less likely to participate in politics than individuals who choose exclusively left- or rightwing blogs.

Building on these arguments, we expect the following patterns to emerge among blog readers. First, there should be substantial homophily. There will be a pronounced association between blog readers' ideological and partisan preferences and the kinds of blogs they read. Liberals and/or Democrats will read mostly leftwing blogs, and conservatives and/or Republicans will read mostly rightwing blogs. We dub these readers "carnivores": they read blogs because these blogs provide them with "red meat" that accords with their partisan or ideological predilections. We expect blog readers to be carnivorous. In contrast, "omnivores," readers who read both leftwing and rightwing blogs, should be relatively rare.

Second, there should be substantial polarization among blog readers. The views of those who read liberal blogs and those who read conservative blogs will overlap little, if at all. Although we cannot determine whether blog reading creates or merely reflects polarization, our findings will still inform normative debates about political discourse and the blogosphere's contribution to that discourse.

Finally, blog readers should participate more in politics than those who do not read blogs. Within the subset of blog readers, we test competing expectations. If blog readers are highly motivated consumers of political information with hardened political beliefs, then there will be little difference between the level of political participation among carnivores and omnivores, or indeed among carnivores on the left and on the right. However, if crosscutting exposure to blogs has a similar impact to that of cross-cutting exposure within personal networks, then, omnivores will be somewhat less fixed in their political identities, more unwilling to undertake political activities that might invite censure from others, and less participatory than carnivores.

\section{Measuring Blog Readership}

Our study improves on existing research about political blog readers by analyzing a more representative sample of Americans and by drawing on detailed information about the blogs they read. For example, some extant research relies on convenience samples of blog readers recruited by placing advertisements on blogs. ${ }^{38,39}$ Our data derive from 
the 2006 Cooperative Congressional Election Study (CCES). The CCES, a collaborative venture involving 39 universities, was carried out by Polimetrix. Respondents were drawn from Polimetrix's PollingPoint panel and were administered the survey on-line. The total sample size was 36,501. (Further details about the survey are in Appendix 1.)

The CCES asked respondents whether they read any blogs and, if so, to write out the names of those blogs in a text box. These questions originated from an earlier survey administered to some PollingPoint panelists. In the CCES sample, $44 \%(16,145)$ were asked this question. Although this is a fraction of the total sample, it is still an extraordinarily large number, relative to conventional polls. A limitation of these data is that the text box had a 64-character limit that may have prevented some respondents from listing all of the blogs they regularly read. ${ }^{40}$ Nevertheless, the CCES presents a uniquely detailed sense of which, if any, blogs people read.

Two research assistants coded each blog that people listed into various categories, isolating political blogs from different kinds of non-political blogs and from other websites that were obviously not blogs. ${ }^{41}$ These political blogs were then coded into left/liberal or right/conservative categories; centrist and/or non-partisan political blogs were also coded as such. We provide a complete list of these codings in an on-line appendix. ${ }^{42}$

Of the 16,145 respondents who were asked whether they read blogs, 5,481 (34\%) answered in the affirmative. Of the blog readers, 3,948 (72\%) wrote in the name of one or more blogs that they read. ${ }^{43}$ We concentrate here on political blogs. Filtering out non-political blogs such as entertainment blogs, sports blogs, and the like leaves us with 2,312 (14\%) blog readers who named explicitly political (partisan and non-partisan) blogs. ${ }^{44}$

Respondents reported reading a wide array of political blogs, 476 in total. Most of these were read by few respondents, and only a few were read by many. The median number of mentions is one, and the seventy-fifth percentile is only three. The most often-cited political blogs are listed in figure 1, which isolates only those blogs named by 30 or more respondents. The most popular blogs (Huffington Post, Daily Kos, The Drudge Report), according to other measures of blog readership, sit atop this list. The number of respondents naming each of these blogs correlates with the unique visitors received by each blog for which public data were available, as measured in the fall of 2006 by Sitemeter, an independent data source $(r=.95)$. Thus the CCES data accurately depict this key feature of blog readership.

\section{Who Reads Blogs?}

The differences between political blog readers on the one hand, and those who either read non-political blogs or no

\section{Figure 1}

Number of respondents who read each blog (including only blogs named by at least $\mathbf{3 0}$ respondents). Well-known and popular blogs, such as The Huffington Post and Daily Kos, were those most often named by

respondents.

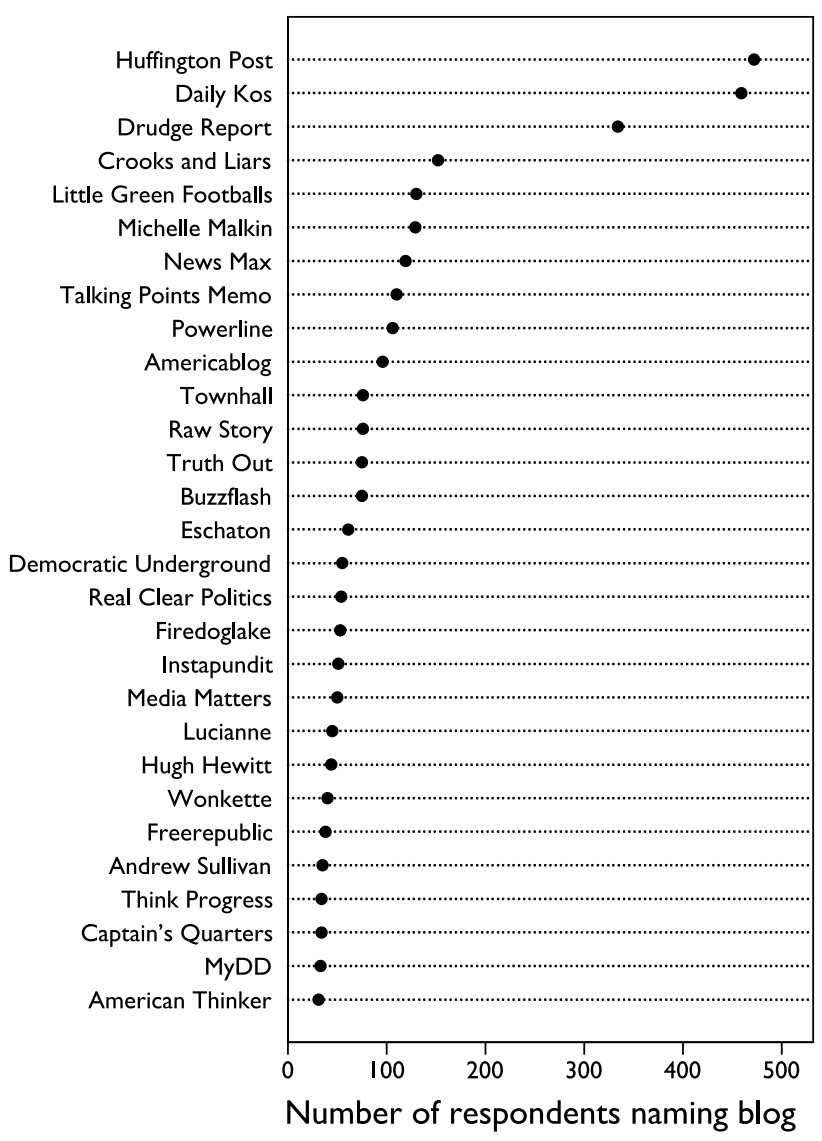

blogs on the other, comport closely with our expectations about the heightened political awareness of blog readers. ${ }^{45}$

Political blog readers are significantly more likely than non-readers to have been educated at a four-year college and to have postgraduate education. ${ }^{46} 36 \%$ of political blog readers have at least a four-year college degree, compared to $29 \%$ of others. Blog readers were a bit younger on average than non-blog readers, but among blog readers, those who read political blogs were older on average than those who did not read political blogs. ${ }^{47}$

As shown in figure 2, no political blog readers claimed to be uninterested in politics; in fact, only a vanishingly small percentage are just "somewhat" interested. Nearly $100 \%$ of blog readers described themselves as very much interested, a substantially larger percentage than among non-readers $(71 \%) .{ }^{48}$ Readers of blogs are more likely than non-readers to lean strongly Democrat and less likely to be independent. Interestingly, blog readers are only 


\section{Figure 2}

The attributes of political blog readers and non-readers. Compared to those who do not read blogs or who read non-political blogs, political blog readers are more interested in politics, more partisan, and more ideological.

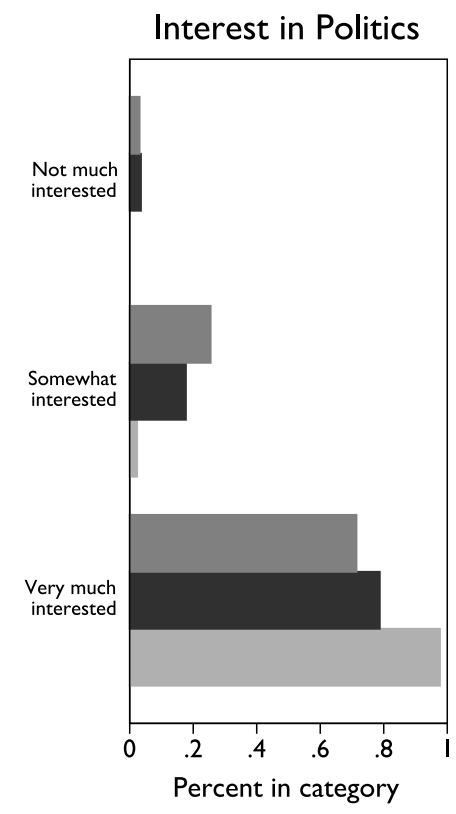

Non-blog readers

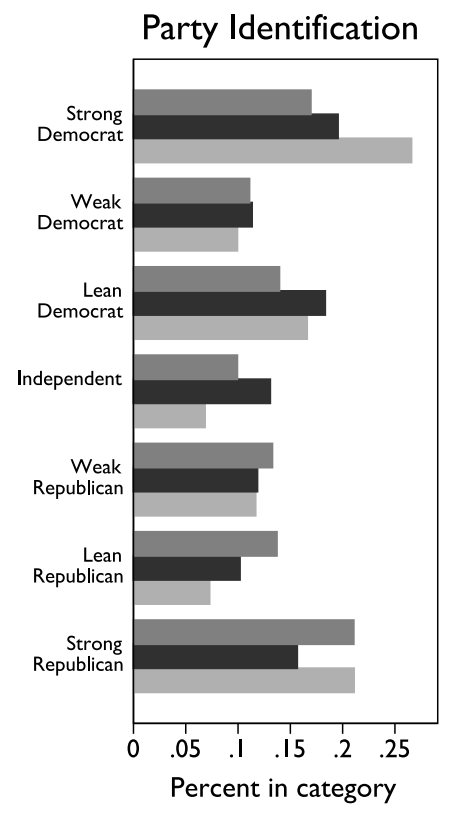

Blog readers, not political blogs

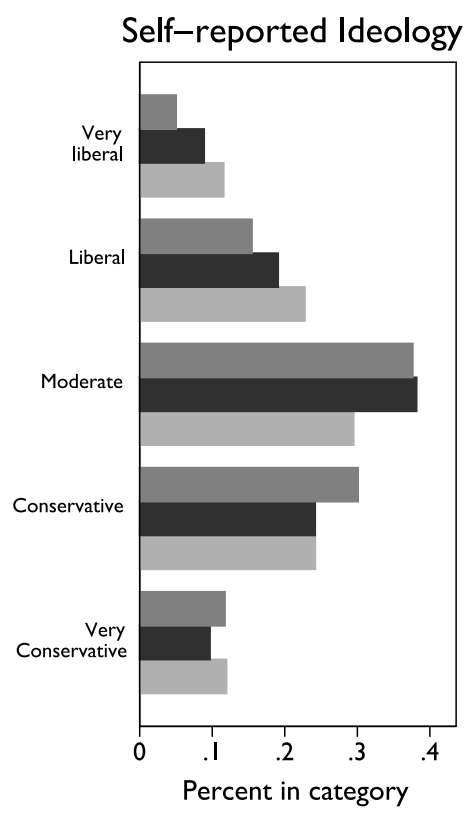

Political blog readers marginally more likely than non-blog readers to be strongly Republican, and are much less likely than blog readers to be weak Republicans. Similarly, blog readers are considerably more likely than non-readers to be either very liberal or liberal and much less likely to be moderate or conservative, although they are slightly more likely than nonreaders to be very conservative. Blog readers are thus more partisan and ideological and, in particular, more liberal or Democratic than non-readers.

These demographic and political differences confirm that political blog readers are more politically aware, more partisan, and more ideological—all of which we would expect if reading political blogs constitutes an intentional search for information.

\section{Homophily and Polarization in the Blogosphere}

Do blog readers tend to select blogs that match their ideological predilection? To answer this question, we determined whether the political blogs listed by each respondent constituted a carnivorous or omnivorous diet. We divided respondents into three categories: those who read exclusively left-leaning blogs, those who read exclusively right-leaning blogs, and those who read both left- and right-leaning blogs. ${ }^{49}$
The results are clear-cut: blog readers are overwhelmingly carnivorous. About $94 \%$ of political blog readers consume only blogs from one side of the ideological spectrum. The remaining $6 \%$ read blogs from both sides. Few blog readers habitually seek out blogs from the other side of the ideological spectrum.

This apparent homophily should derive from selective exposure, as carnivores choose blogs whose political perspective matches their own, and should produce a pattern of political polarization. To test these expectations, we selected three measures of political preferences-party identification, self-reported ideology on the liberal-conservative spectrum, and an ideology scale based on issue positionsand then compared the distribution of each measure across these categories of blog consumption. ${ }^{50}$

Figure 3 presents these distributions as "violin plots", 51 which combine standard density plots and box plots into a single diagram. The shaded areas, akin to the violin's body, represent the density. Inside the shaded area are a single dot, representing the median; a dark box, capturing the interquartile range; and a thin line extending from the lower adjacent value to the upper adjacent value. ${ }^{52}$

Each of these three plots conveys striking evidence of selective exposure and political polarization. Left-wing blog readers are overwhelmingly liberal and Democratic, and right-wing blog readers are overwhelmingly conservative 


\section{Figure 3}

Densities of political attributes by blog diet. Readers of left-wing blog are strongly liberal and Democratic, while readers of right-wing blogs are strongly conservative and Republican. There is almost no ideological overlap between these two groups. Those who read both left- and right-wing blogs are more widely dispersed, but lean toward the liberal or Democratic side. This figures provides evidence of selective exposure and depicts a highly polarized blogosphere.
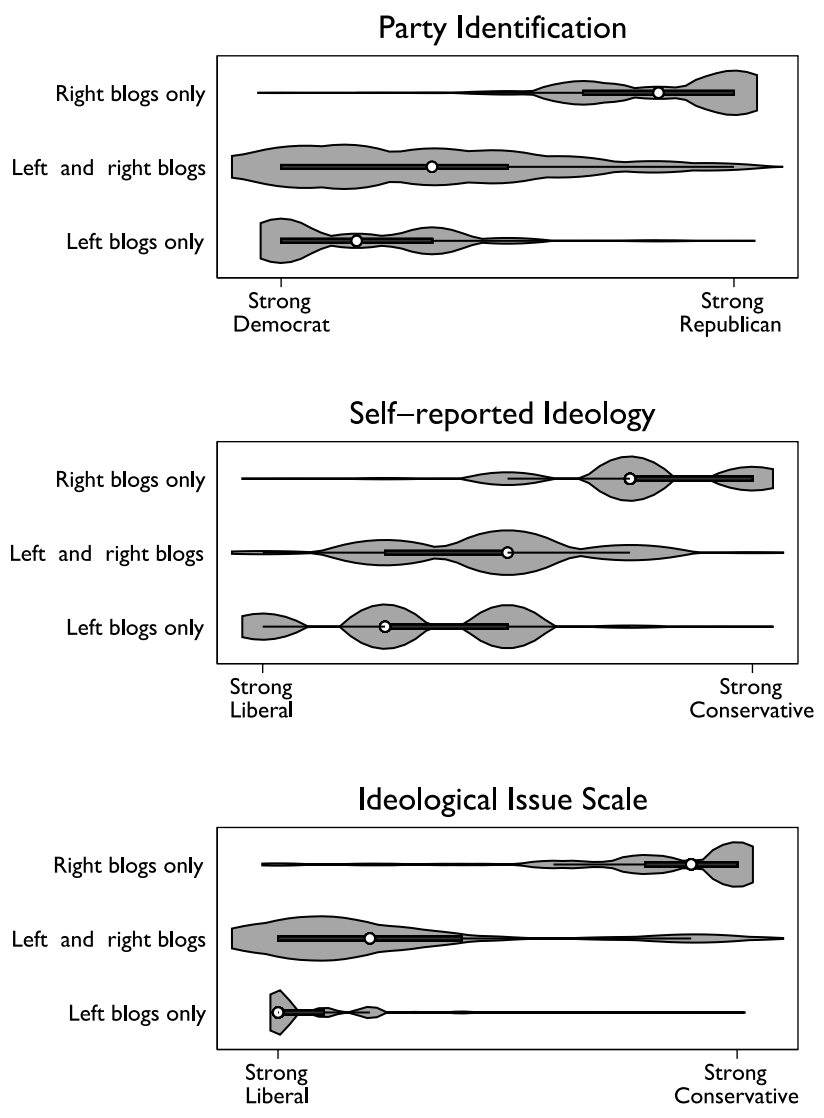

and Republican. Those who read both kinds of blogs are more widely dispersed across the ideological and partisan spectrum, although they also tend to be liberal and Democratic. Thus, it is clear that most carnivores - that is, most political blog readers—read political blogs that provide ideological comfort.

The blogosphere also appears highly polarized. There is little overlap between left- and right-wing blog readers in terms of party identification or ideology. The same pattern emerges if we isolate the six political blogs most popular in our sample, and compare the ideological distribution among readers of those blogs. Figure 4 presents similar violin plots of the issue-based ideological scale. Readers of the three liberal blogs (Huffington Post, Daily Kos, and Crooks and Liars) are crowded on the left; readers of the three conservative blogs (The Drudge Report, Michelle Malkin, and Little Green Footballs) are crowded on the right. Again, the respective ideological distributions of leftand right-wing blog readers overlap little, if at all.

But is the apparent polarization of blog readers any greater than among non-readers, consumers of other news media, or political elites? To gain some comparative perspective, we first separated political blog readers from those who do not read political blogs, and then compared the issue-based ideological profile of Democrats and Republicans in each group. Figure 5 demonstrates that political blog readers are more polarized. Among both Democrats and Republicans, the median political blog reader is located closer to the ideological pole and the density is tightly distributed close to the pole. By contrast, partisan non-readers, while skewing in the expected ideological direction, are less polarized on average as well as much more dispersed.

Second, we compared blog readers to television news consumers. Relying on the same ideological scale, figure 6 summarizes the distribution across viewers of each major television news outlet, including the three broadcast networks (ABC, $\mathrm{CBS}$, and $\mathrm{NBC}$ ), the three cable networks (CNN, Fox, and MSNBC), and PBS — alongside the familiar distributions among carnivorous and omnivorous blog readers. Viewers of each news network, with the exception of Fox News, skew to the left; Fox News viewers skew to the right, as one would expect. Thus, there is evidence of selective exposure and polarization among television news viewers.

However, the ideological distribution of each outlet's consumers is both centered farther from the ideological pole and more widely dispersed than are the ideological distributions among blog carnivores. As the lower panel of this figure demonstrates, the median "ideal point" of right-wing blog readers is to the right of Fox News viewers. Similarly, left-wing blog readers are more liberal than consumers of these mainstream news channels. ${ }^{53}$ Only the small number of omnivores resemble these other news consumers. ${ }^{54}$

Finally, we can compare blog readers to political elites, namely US senators. This is a particularly interesting exercise given the evidence of, and concern about, partisan polarization in the Congress. ${ }^{55}$ Because the CCES designed issue questions based on roll call votes, we can examine the votes of US Senators on these same roll calls and construct a similar ideological scale. In this case, the scale is analogous to NOMINATE scores, ${ }^{56}$ although based on far fewer votes so as to be comparable to the measure constructed for respondents. Figure 7 presents the distributions for Republican and Democratic senators and for blog readers.

As in most scalings of roll call votes in recent congresses, senators appear quite polarized. Few Democrats 


\section{Figure 4}

Densities of ideology among readers of 6 popular political blogs. The distributions among liberal and conservative readers of 6 popular political blogs are highly polarized.

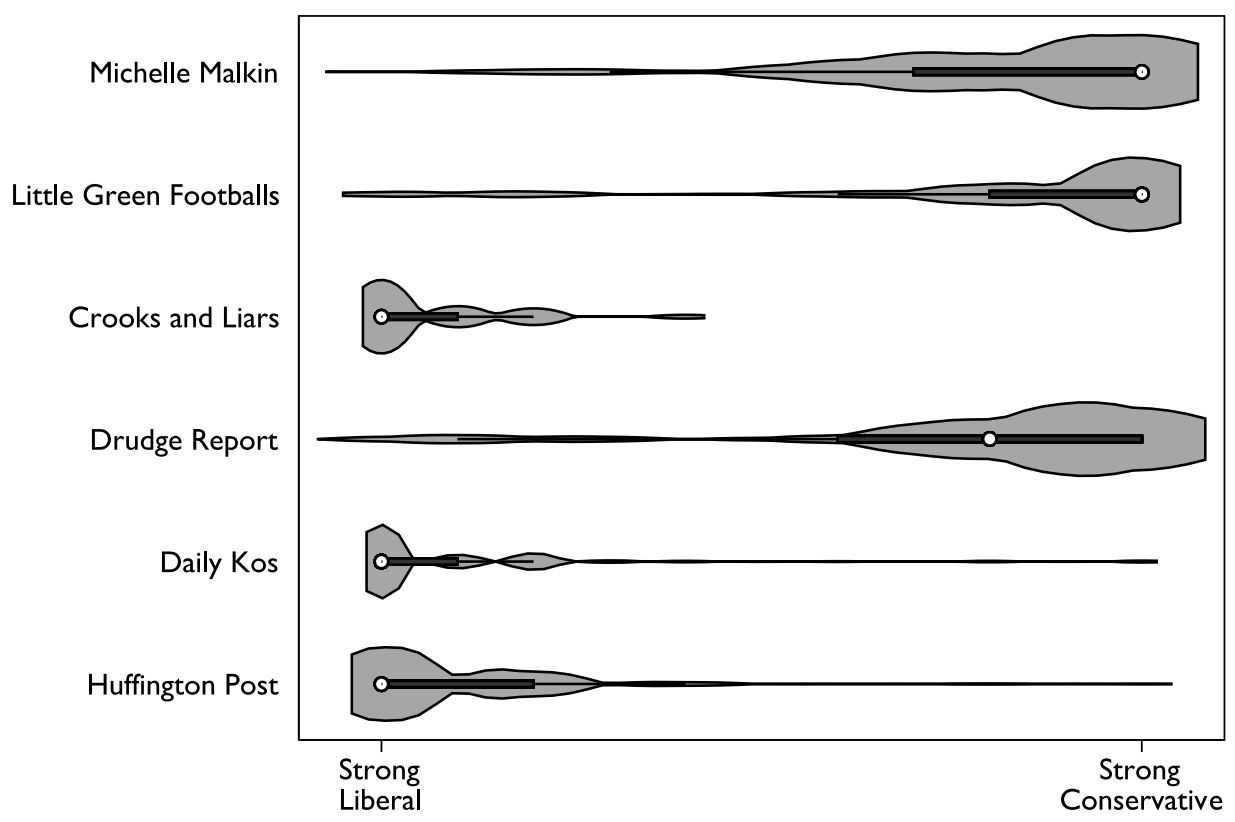

\section{Figure 5}

Densities of ideology by blog readership and party. Blog readers in both parties are more ideologically polarized than non-readers.
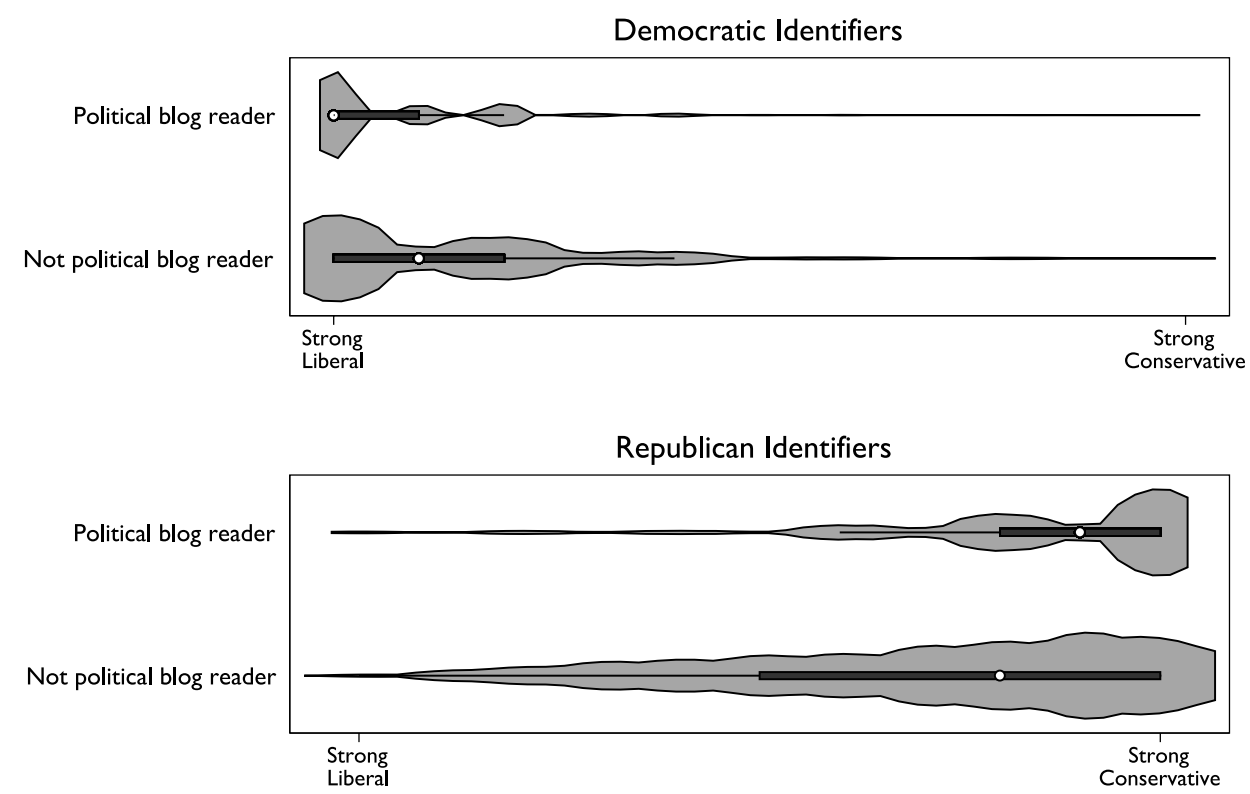

scale right of any Republicans and few Republicans scale left of any Democrats. ${ }^{57}$ The median Democrat is at the leftmost point, and the median Republican is at the rightmost point. The senators of each party are almost all clus- tered on separate halves of the ideological spectrum. Among blog readers, the median left-wing reader is at the leftmost point, as is the median Democratic senator, while the median right-wing reader is just to the left of the median 


\section{Figure 6}

Densities of ideology among news consumers and blog readers. Left- and right-wing blog readers are more densely concentrated around the relevant ideological pole than are consumers of these television news programs. The blogosphere appears more polarized than does television news.
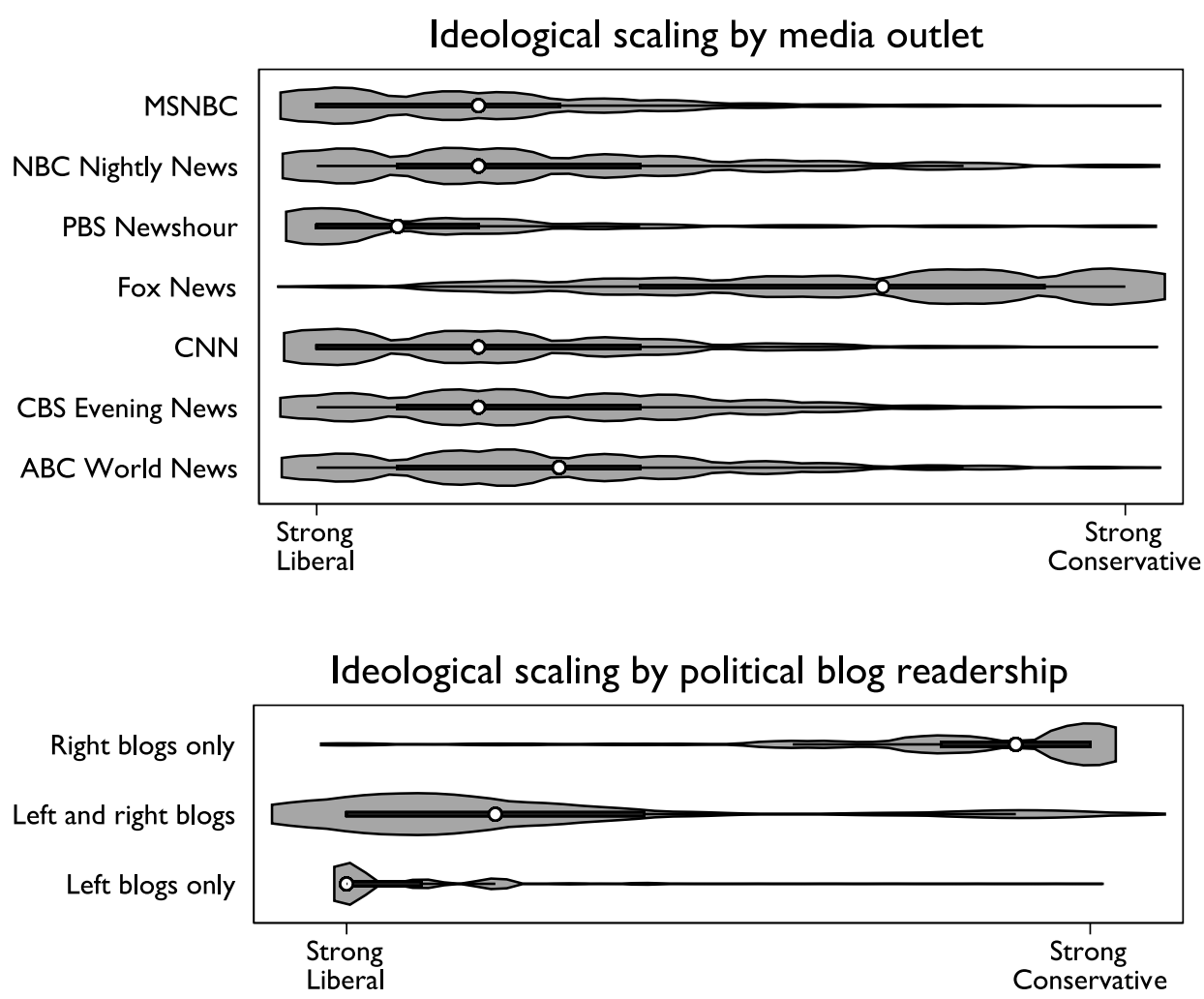

Republican senator. In this sense, blog readers are slightly less polarized than US senators. However, the ideological dispersion of senators is roughly similar to that of blog readers. Left blog readers are somewhat more homogeneous than Democratic senators, and right blog readers are slightly less homogeneous than Republican senators. ${ }^{58}$

Thus, political blog readers behave as highly motivated and politically interested citizens would be expected to behave: they tend to select political blogs that dovetail with their ideological views. Blogs may push readers' political opinions even farther toward one end of the ideological spectrum, although we cannot investigate this possibility using these data. But regardless of the direction(s) of causation, the end result is the same: blog readers appear highly polarized relative to non-blog readers and other news consumers, and are very nearly as polarized as US senators. Because the typical blog reader is rarely exposed to the views of blogs on the opposite side of the political spectrum, the deliberative potential of blogs likely suffers. ${ }^{59}$

\section{Political Participation and the Blogosphere}

Even if blogs are unproductive forums for deliberation, they could be catalysts for participation. Although we cannot establish any causal relationship, we can evaluate patterns of association in light of existing hypothesesspecifically, whether exposure to competing viewpoints is associated with dampened participation, or whether carnivores and omnivores are equally and highly participatory.

We first compare those who do not read blogs, those who read non-political blogs, and those who read political blogs. Political blog readers, whom we know to be more partisan and interested in politics than the other two groups, should participate the most. We measure participation as an additive scale of three acts relevant to the 2006 election: voting, donating to a candidate, and trying to persuade someone to vote for a particular candidate.

As figure 8 demonstrates, non-readers participate the least: an average of 1.8 acts. Those who read non-political blogs participate slightly more often $(2.0$ acts). Political 


\section{Figure 7}

Densities of ideology for US senators and blog readers. The densities of ideology for blog readers and senators are nearly equally polarized.

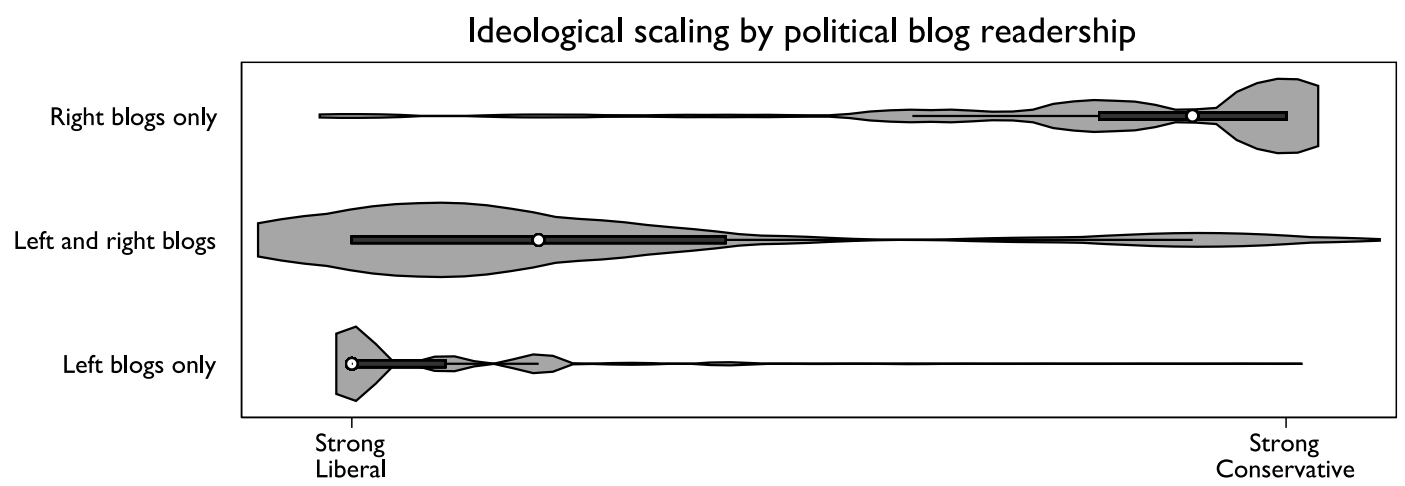

Ideological scaling by party of senator

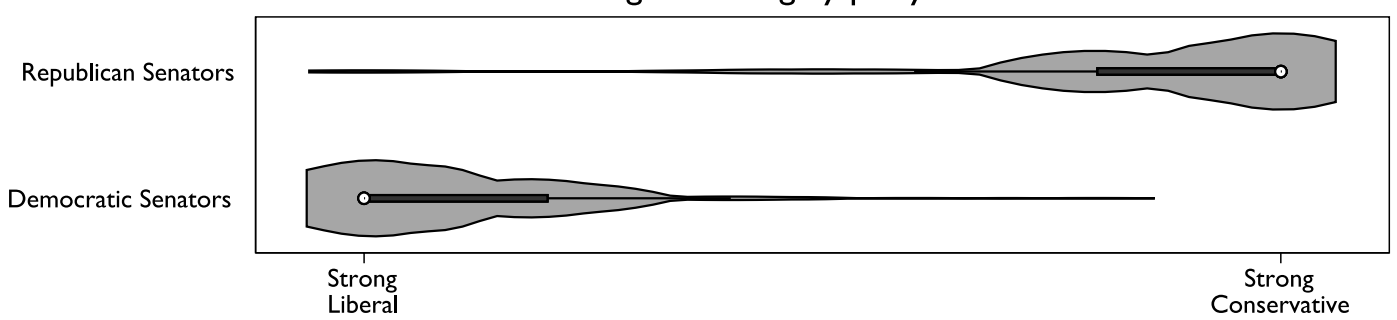

blog readers participate most often $\left(2.3\right.$ acts). ${ }^{60}$ When we control for education, partisan intensity, income, and age, the mean differences remain statistically significant. ${ }^{61}$

The next question is whether the participation of political blog readers is correlated with their blog diets. Figure 9 presents histograms and means for omnivores and both groups of carnivores. The pattern of results does not suggest any demobilizing consequences of exposure to competing views. Left-wing carnivores and omnivores participate at indistinguishable rates (averages of 2.4 and 2.3 acts, respectively). Instead, it is right-wing carnivores who participate at a lower rate $(2.1 \mathrm{acts})$, one that is statistically distinguishable from the other groups. ${ }^{62}$

Thus, the effects of competing viewpoints in personal political networks ${ }^{63}$ do not carry over to networks of blogs. Blog readers may be less likely to manifest either of the attributes that Mutz suggests lead those who experience competing viewpoints to participate at lower rates. As politically interested partisans, blog readers are unlikely to experience much uncertainty about their political choices. Even exposure to divergent ideological viewpoints will not cause them to hesitate in choosing a candidate and working on that candidate's behalf. Blog readers are also likely to have less incentive to avoid conflict, as interactions on political blogs typically do not involve the sorts of intimate relationships that exist within personal political networks (e.g., among family or friends). ${ }^{64}$
At the same time, our results do not show blog readers to be a homogeneous group of political activists. There is variation among blog readers based on their diets, specifically differences between left-wing carnivores and omnivores on the one hand, and right-wing carnivores on the other. One plausible explanation would invoke the different agendas of left- and right-wing blogs. Several prominent left-wing blogs, notably Daily Kos, are explicitly interested in building a progressive movement. These blogs often focus on political mobilization, identifying progressive candidates and encouraging readers to donate to and work for them. Conservative blogs focus less on traditional means of mobilization, often serving instead as forums for commentary. This generalization receives support both from bloggers on both left and right ${ }^{65}$ and empirical research. Wallsten ${ }^{66}$ finds that although prominent blogs engage in relatively little mobilization, leftwing blogs engage in twice as much mobilization as right-wing blogs. Benkler, Shaw and Stodden ${ }^{67}$ find that during the 2008 campaign, nearly one half of left-wing blogs asked their readers to engage in political action, while less than one fifth of right-wing blogs did so. There were even starker differences in left- and right-wing blogs' willingness to raise funds for political candidates. Thus readers exposed to left-wing movement-building blogs will be more likely to participate than readers exposed only to right-wing blogs. Clearly, though, further research 


\section{Figure 8}

Number of participation acts by blog readership. Those who read political blogs tend to engage in more political acts than those who read non-political blogs and those who read no blogs. The differences among these groups are statistically significant.
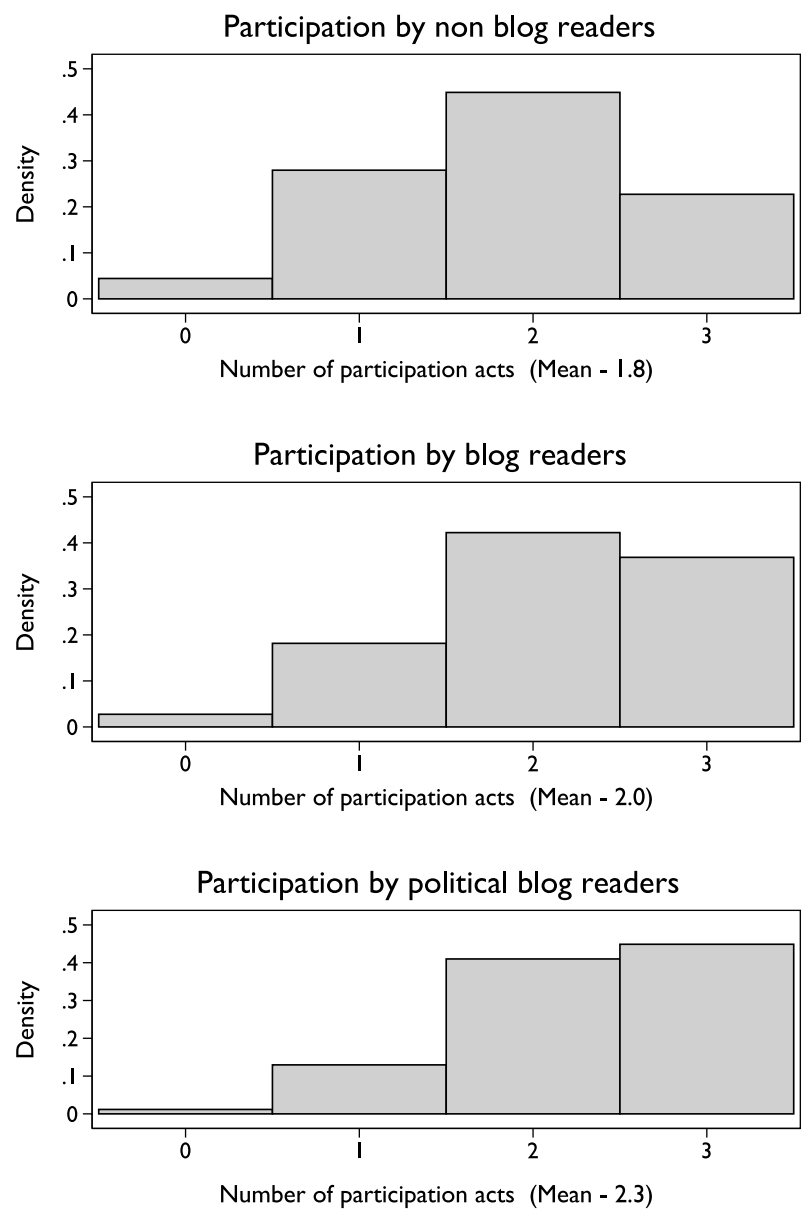

is necessary to further elucidate the precise causal relationships involved.

\section{Conclusion}

This detailed look at political blog readers demonstrates again the difficulty of realizing multiple democratic ideals simultaneously. By one normative standard, that of political participation, the blogosphere appears to be exemplary. Blog readers are highly likely to participate and, even if we cannot definitively claim that blogs themselves increase their readers' participation, they likely nurture blog readers' intrinsic interest in politics and suggest avenues into which blog readers can direct their activism. We do not find that exposure to diverse viewpoints reduces participation: blog readers who read both left- and right-

\section{Figure 9}

Participation by diet. Participation is highest

among left-leaning carnivores and

omnivores, but lower among right-leaning

carnivores. Cross-cutting exposure does not appear to demobilize blog readers. The difference between right-leaning carnivores and the other two groups is statistically significant.
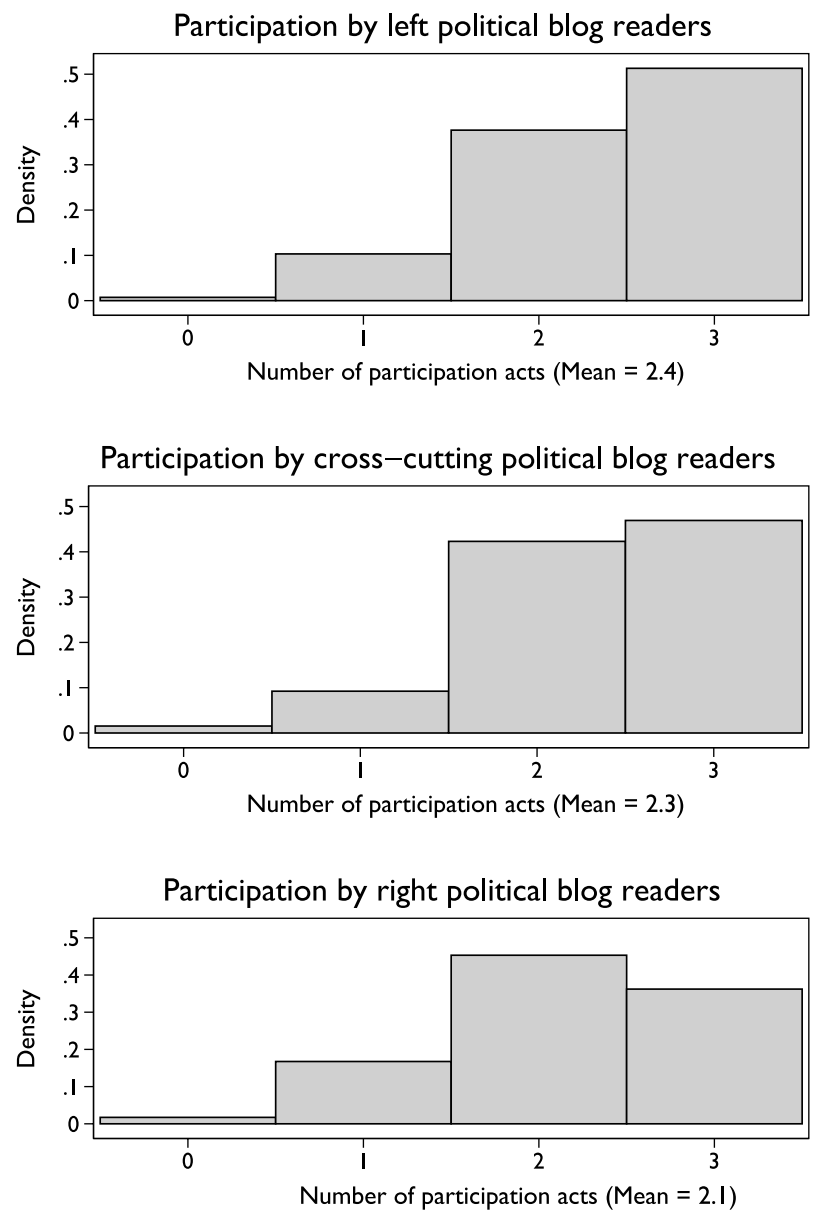

wing blogs participate as much as those who read leftwing or right-wing blogs. Instead, readers of leftwing blogs and cross-cutting readers participate more than readers of right-wing blogs, which cannot be explained by a shared interest in politics among blog readers. A potential explanation is the social movement structure among left-wing bloggers and blog readers, and the absence of such a structure among right-wing bloggers and blog readers. This explanation is supported by other scholars' empirical research, which suggests that there are strong differences between left-wing and right-wing bloggers' willingness to exhort their readers to engage in political action. ${ }^{68}$ The left blogosphere in particular has some of the qualities of a 
more traditional social movement, which could inspire people to participate in politics.

But by the standards of some political deliberation theorists, the blogosphere falls short. Deliberation entails a dialogue between opposing views, but blog authors tend to link to their ideological kindred and blog readers gravitate to blogs that reinforce their existing viewpoints. Both sides of the ideological spectrum inhabit largely cloistered cocoons of cognitive consonance, thereby creating little opportunity for a substantive exchange across partisan or ideological lines. The potential trade-off between participation and deliberation noted by Mutz ${ }^{69}$ appears as salient in the blogosphere as in personal networks.

Discourse in the political blogosphere is more compatible with accounts that emphasize the importance of clashes of interest, sharp disagreement, and conflict in deliberation, and suggest that some of the claims of more optimistic scholars of deliberation are utopian. ${ }^{70}$ Such accounts imply a greater potential for deliberative exchange as a result of blogs, as do accounts that stress the normative potential of political parties. ${ }^{71}$ Even so, although political blogs, and the internet generally, facilitate information search and acquisition-thereby conceivably enhancing people's ability to learn about opposing points of view-few readers avail themselves of these benefits. Blog readers thus have less opportunity for revising their opinions than they might otherwise have. Some bloggers are explicitly willing to forego an exchange among opposing views to promote partisan engagement. As a prominent blogger on The Daily Kos describes ${ }^{72}$ on March 3 2008 that site:

This site is primarily a Democratic site, with a heavy emphasis on progressive politics. It is not intended for Republicans, or conservatives. ... This is not a site for conservatives and progressives to meet and discuss their differences. . . . Conservative debaters are not welcome simply because the efforts here are to define and build a progressive infrastructure, and conservatives can't help with that. There is, yes, the danger of the echo chamber, but a bigger danger is becoming simply a corner bar where everything is debated, nothing is decided, and the argument is considered the goal. The argument, however, is not the goal, here. This is an explicitly partisan site: the goal is an actual infrastructure, and actual results.

Strong partisanship of the kind expressed by this blogger may have substantial normative benefits. Rosenblum ${ }^{73}$ argues that partisans help construct political cleavages, creating order in what would otherwise be an unruly mess of inchoate and unrelated issues. In her account, conflict between clearly articulated political viewpoints can have important epistemic benefits. If so, then bloggers and blog readers play a valuable democratic role. ${ }^{74}$

Even for scholars who are uninterested in partisanship as such, our findings speak to current debates at the intersection of political science and political theory. As Dennis Thompson ${ }^{75}$ observes:
The conflict between deliberation and participation does not of course reflect a universal law. We do not yet know enough about how general the conflict is-under what specific conditions is it more or less likely to appear. Is it more likely in discussions about certain kinds of issues? Is it more common in discussions among ordinary citizens than political leaders? . . The empiricist's answer to the theorist's general question should prompt the theorist to ask more specific questions. The theorist needs the answers in order to evaluate how serious the conflict of values is, and what steps are worth taking to overcome it.

Given the paucity of research on political blogs, there is abundant room for future research that would speak to the questions Thompson raises. A central task is to understand the causal impact of reading blogs. One research design would involve a controlled experimental setting, in which media choices could be structured and their consequences measured. A second task is to differentiate among blogs, particularly in terms of how much and how they engage opposing arguments. Some left-wing and rightwing blogs may better approximate deliberative engagement with other blogs of different persuasions. This could in turn affect the political behavior of their readership. A third task is to understand how blogs do or do not stimulate participation. This could even be done with observational data-e.g., by measuring a candidate's daily fundraising totals and comparing those trends to trends in solicitations by the candidate and by sympathetic blogs. A fourth is to see whether insights from the social movement literature ${ }^{76}$ can be extended to electronically mediated forms of social solidarity. A fifth is to compare the consequences of websites that explicitly emphasize political discussion with the consequences of non-political websites (where political debates sometimes arise). ${ }^{77}$ These and similar research projects will become all the more important, as the media environment continues to shift toward internet-based sources of information and as these sources become even more critical to the communication strategies of political actors.

\section{Appendix 1. The 2006 Congressional Cooperative Election Survey}

The 2006 CCES was a collaborative venture involving 39 universities in the United States, with Stephen Ansolabehere of MIT as the principal investigator. ${ }^{78}$ Each university designed a module of questions that was given to 1,000 respondents; in addition, the combined sample of approximately 39,000 respondents was asked a common module of questions, which always preceded each university's module. The fieldwork for the survey was carried out by Polimetrix, Inc., of Palo Alto, CA. The survey was fielded in October and November of 2006.

The CCES was administered on-line. Respondents were selected from the Polimetrix PollingPoint Panel pool of several hundred thousand individuals who have volunteered or been recruited to participate in occasional on-line 
polls. Respondents were selected for the CCES using the following sampling procedure. First, a random subsample was drawn from the 2004 American Community Study, which is conducted by the US Census Bureau and has a sample size of nearly 1.2 million and a response rate of 93 percent. Then, for each person in this sub-sample, the closest matching respondent was located in the PollingPoint Panel using a function that minimized the "distance" between the ACS and PollingPoint respondents based on several variables, including gender, race, age, marital status, education, party identification, and ideology. (Party identification and ideology were imputed for ACS respondents using demographic variables.) Finally, as is common in many surveys, post-stratification weights were created for the CCES respondents, matching the CCES marginals to the ACS marginals for gender, education, race, and age. For more on sampling matching and weighting, see Rivers. ${ }^{79}$ Thus, the distributions of these variables closely match national figures for the adult populatione.g., slightly more than half of the CCES sample (52\%) is female; $25 \%$ of respondents have at least a college degree; $72 \%$ are white; and $8 \%$ are aged $18-24$.

Two initial investigations of non-probability Internetbased samples ${ }^{80}$ find that their results may differ from traditional probability samples in both the mean levels of particular attributes and in the relationships among different attributes (e.g., between political predispositions and vote choice), although Sanders et al. reach a more sanguine conclusion about the substantive importance of such differences than Malhotra and Krosnick. Of course, there is no way to determine, except perhaps when examining the marginals of vote choice or turnout, which kind of poll will consistently produce results closer to the "truth."

To date, forecasts of election outcomes using Polimetrix data have proven quite accurate. ${ }^{81}$ Moreover, comparisons of the CCES with other surveys, such as the American National Election Studies and the 2006 exit polls, suggest that the CCES produces similar distributions of opinion with regard to attitudes toward Bush and the Iraq War ${ }^{82}$ and stereotypes of whites, blacks, Hispanics, and Asians. ${ }^{83}$ This suggests that the mode of the survey does not affect the mean levels of at least some key attitudes.

\section{Notes}

1 The authors are listed in order of their degree of familiarity with the intricacies of Big Ten football.

2 Farrell and Drezner 2008.

3 Cohen 1989, Fishkin 1995.

4 Ackerman and Fishkin 2004.

5 e.g. Cohen 1989.

6 e.g., Putnam 2000, Skocpol 2003.

7 Macedo et al. 2005.

8 Mutz 2006.

9 Prior 2007.
10 Prior 2007, 3.

11 Bloggers can also affect the content of readers' comments by enforcing particular rules for commenting, deleting offending comments, and banning habitual offenders.

12 Shirky 2003, Glance and Adamic 2005, Herring et al. 2005, Farrell and Drezner 2008; Hargittai, Gallo and Kane 2008, Hindman 2008.

13 On homophily in social networks, see McPherson, Smith-Lovin, and Cook (2001).

14 Glance and Adamic 2005; Hargittai, Gallo, and Kane 2008, Perlmutter 2008.

15 see e.g. Bimber 2000, Agre 2004, Papachrissi 2002, Dahlgren 2005, Meraz 2007, Hindman 2008.

16 Sunstein 2008.

17 Habermas 2006a, 4.

18 Habermas 2006b, 426.

19 ibid.

20 Benkler 2006.

21 Woodly 2008.

22 e.g., Mutz 2006; Prior 2007; Zaller 1992.

23 Pole and McKenna (2007) do examine the participation of bloggers in politics, but do not study the broader population of blog readers.

24 Downs 1957.

25 More specifically, he characterizes free information in this way. Arguably, blogs constitute free information, leaving aside capital investment in a computer and internet connection. Even that is essentially subsidized by employers for many people.

26 Zaller 1992.

27 Prior 2007.

28 Downs 1957, 213.

29 see Wallsten 2007.

30 Zaller 1992.

31 Lodge and Taber 2007.

32 Lodge and Taber 2007, 34.

33 e.g., Taber and Lodge 2006.

34 Mutz 2006.

35 Mutz 2006, 48.

36 Mutz 2006.

37 Delli Carpini and Keeter 1996; Prior 2007; Zaller 1992.

38 Johnson and Kaye 2004.

39 The online advertising company Blogads has conducted a series of surveys using a similar sampling method. See http://www.blogads.com/survey/ blog_reader_surveys_overview.html for links to these surveys and their main findings.

40 This may possibly affect our findings regarding the numbers of 'carnivores' and 'omnivores' in the blogosphere; people who read very many blogs of both left and right may preferentially list the blogs closer to their ideological position in the text box, thus artificially inflating the number of carnivores relative 
to omnivores. However, the average number of characters in completed responses was only 23 characters, and only $7 \%$ of those naming blogs actually wrote until the character limit was reached. We are grateful to Marc Lynch for raising this point. An anonymous reviewer also notes that the text box forces respondents to recall the blogs they read and take the time to write them down. Had we presented respondents with a pre-determined list of blogs, they could perhaps have remembered more blogs and noted them more efficiently. This mode of data collection does have its benefits. It also has potential liabilities. One is the challenge of itemizing relevant political blogs, especially given that our respondents named almost 500. A second is the costs entailed for respondents in reviewing a long list. A third is that similar measures of media exposure-i.e., naming a media outlet or event and then asking respondents whether they watched, read, or heard it - tends to produce substantial overreporting (see, e.g., Vavreck 2007). Ultimately, there may be merit in both approaches. Better measurement remains a significant task for future research.

41 As we have noted, we consider blogs to be political blogs if they focus on national, state or local politics. For example, we coded as political blogs such sites as Daily Kos, Real Clear Politics, and RedState, which are primarily concerned with elections, and blogs such as The Washington Monthly, Postmodern Conservative, and Matthew Yglesias, which cover party politics and policy issues. Blogs that engage electoral politics and policy only occasionally-e.g., many parenting blogs-are not counted as political blogs. As always with coding of complex categories, we made some judgment calls, e.g., we did not code the popular technology blog, BoingBoing, as a political blog, even though it sometimes covers political issues in a trenchant fashion, since it describes itself as a "directory of wonderful things." Others might reasonably disagree with the way that we define politics; for example, feminist scholars might view blogs about parenting as eminently political. However, for our specific purposes, a narrower definition makes better sense.

42 The coding appendix can be obtained here: http:// www.henryfarrell.net/Aspaper/blogLRcodes.pdf

43 More respondents than that entered text that we did not code, such as "rather not say," "none of your business," "what a blogs," and so forth.

44 This almost surely understates the number of respondents who use blogs to read about politics. Some respondents gave answers such as "news blogs" or "Washington Post." These respondents may be using these sources to read about politics, but they may be reading about movies or sports instead, so we include such cases in omnibus categories and do not analyze them here.

45 Comparisons are made with the reader groups as defined above, using sampling weights. All of the subsequent analysis uses sampling weights unless otherwise specified. We illustrate our results graphically, following the advice of Gelman et al. (2002) and Kastellec and Leoni (2007).

46 The percentage of blog readers with both completed degrees at a four-year college and post graduate education is considerably lower than that reported in previous advertising surveys; we strongly suspect that this reflects the sampling problems in these surveys discussed above.

47 We assessed these comparisons formally with a series of difference in means tests, comparing blog readers to non-blog readers and political blog readers to non-political blog readers across four demographic variables, gender, age, income, and education. From these eight tests, only gender and income in the blog reader/non-blog reader comparison was not statistically significant at the .01 level. The substantive differences were quite small, however-e.g., a 3-year age gap between the political blog readers and the non-political blog readers.

48 However, the political interest question was asked of only a small fraction of the sample, so results using this item should be treated with caution.

49 The vast majority (90\%) of political blog readers fell into one of these three categories. The remaining $10 \%$ read some combination of left- or right-leaning blogs and political blogs that did not have a clear ideological disposition. There were no statistically significant differences across these three categories in gender, age, education, or income.

50 The ideology scale is a simple additive scale based on questions asking respondents whether they would support a ban on "partial-birth" abortions, funding for stem cell research, withdrawing troops from Iraq, raising the minimum wage, and extending capital gains tax cuts. The questions were designed to mimic the content of actual roll call votes in the Senate. The scale is reliable; Cronbach's $(\alpha)=.84$.

51 see Hintz and Nelson 1998.

52 In a box plot, the upper adjacent value is the largest value in the upper whisker; the lower adjacent value is the smallest value in the lower whisker. Put differently, the upper adjacent value is the largest value less than or equal to the value of the third quartile plus 1.5 times the interquartile range. The lower adjacent value is defined in parallel fashion.

53 Simple difference in means tests indicate that the differences between PBS watchers and left blog readers and Fox News watchers and right blog readers on the ideological scale are statistically significant. 
54 Blog readers may resemble consumers of more traditional partisan publications, including small-to-midsized political journals such as The New Republic, The American Prospect, The National Review and The Weekly Standard. Blog readers may also have more exposure to diverse points of view than readers of these print magazines. Unfortunately, we lack data on readers of these journals. We are grateful to Steven Berlin Johnson for this point.

55 Hetherington 2001; McCarty, Poole, and Rosenthal 2006; Sinclair 2006; Theriault 2008.

56 Poole and Rosenthal 1997.

57 One notable exception is Lincoln Chafee (R-RI) who voted with the Democrats on all five issues.

58 The differences in the standard deviations for both comparisons is about .1 on a -1 to +1 scale, with the within-group standard deviations ranging from .26 for left blog readers to .48 for right blog readers. Both Senate parties have standard deviations of approximately .35 .

59 Of course, if political blogs made it a practice to link to blogs on the other side of the spectrum, readers would encounter disparate opinions in a more accidental fashion. However, as we discussed earlier, studies of blogs suggest that cross-cutting linkages are uncommon.

60 A simple regression confirms that the differences among each pair of groups are statistically significant at the .01 level.

61 We used multiple regression here, with the party identification scale folded in order to measure partisan intensity.

62 We again use multiple regression, comparing the mean differences among the types of blog readers while controlling for education, age, income, and partisanship. The adjusted mean participation rate of right blog readers is significantly less than cross-cutting and left blog readers using an $(\alpha)$ level of .01 .

63 Mutz 2006.

64 Mutz also finds that the demobilizing effects of cross-cutting exposure are much more pronounced among the conflict-avoidant. Blog readers, by dint of their greater partisanship and attraction to a forum in which conflict is often heated, are unlikely to find conflict inherently distasteful.

65 e.g. Bowers and Stoller 2005, Ruffini 2008.

66 Wallsten 2007.

67 Benkler, Shaw and Stodden unpublished.

68 Barnes and Kaase 1979.

69 Mutz 2006.

70 Knight and Johnson n.d.

71 Cohen 1989.

72 Downloaded from http://dkosopedia.com/wiki/ Troll_rating on March 32008.
73 Rosenblum 2008.

74 See further the debate between Farrell 2009 and Rosenblum 2009.

75 Thompson 2008, 512-513.

76 e.g., McAdam, Tarrow, and Tilly 2001.

77 e.g. Wojcieszak and Mutz 2009.

78 Ansolabehere 2006.

79 Rivers 2006.

80 Malhotra and Krosnick 2007; Sanders et al. 2007.

81 Polimetrix 2005.

82 Jacobson 2007.

83 Sides and Gross 2007

\section{References}

Ackerman, Bruce A. and James A. Fishkin. 2004. Deliberation Day. New Haven: Yale University Press.

Adamic, Lada A., and Natalie Glance. 2005. "The Political Blogosphere and the 2004 US Election: Divided They Blog." Working paper.

Agre, Philip E. 2004. The Practical Republic: Social Skills and the Progress of Citizenship. In Community in the Digital Age, eds. Andrew Feenberg and Darin Barney. New York: Rowman and Littlefield, 201-24.

Ansolabehere, Stephen. 2006. Cooperative Congressional Election Study, Common Content. [Computer File] Cambridge, MA: M.I.T. [producer] http://web.mit. edu/polisci/portl/cces/commoncontent.html (Release 2: November 14, 2007).

Barnes, Samuel H. and Max Kaase. 1979. Political Action: Mass Participation in Five Western Democracies. Beverly Hills, CA: Sage.

Benkler, Yochai. 2006. The Wealth of Networks: How Social Production Transforms Markets and Freedom. New Haven: Yale University Press.

Benkler, Yochai, Aaron Shaw and Victoria Stodden. Unpublished. A Tale of Two Blogospheres: Discursive Practices on the Left and Right. Cambridge MA: Berkman Center, Harvard.

Bimber, Bruce. 2000. The Study of Information Technology and Civic Engagement. Political Communication 17 (4): 329-333.

Cohen, Josh. 1989. Deliberative Democracy and Democratic Legitimacy. In The Good Polity, eds. Alan Hamlin and Philip Pettit. Oxford: Blackwell, 17-34.

Dahlgren, Peter. 2005. The Internet, Public Spheres, and Political Communication: Dispersion and Deliberation. Political Communication 22 (2): 147-62.

Delli Carpini, Michael X. and Scott Keeter. 1996. What Americans Know About Politics and Why It Matters. New Haven: Yale University Press.

Dewey, John. 1954[1927]. The Public and Its Problems. Athens, OH: Swallow.

Downs, Anthony. 1957. An Economic Theory of Democracy. New York: Harper \& Row. 
Drezner, Daniel and Henry Farrell. 2008. Introduction: Blogs, Politics and Power: A Special Issue of Public Choice. Public Choice 134(1): 1-13.

Farrell, Henry. 2009. "Partisanship and Extremism." Cato Unbound. http://www.cato-unbound.org/2009/ 02/06/henry-farrell/partisanship-and-extremism/.

Farrell, Henry and Daniel Drezner. 2008. The Power and Politics of Blogs. Public Choice 134(1): 15-30.

Fishkin, James. 1995. The Voice of the People: Public Opinion and Democracy. New Haven: Yale University Press.

Gelman, Andrew, Christian Pasarica, and Rahul Dodhia. 2002. Let's Practice What We Preach: Turning Tables into Graphs. The American Statistician 56(2): 121-30.

Habermas, Jurgen. 1984. The Theory of Communicative Action. Boston: Beacon.

Habermas, Jurgen. 2006a. Preisrede von Jürgen Habermas: anlässlich der Verleihung des Bruno-Kreisky-Preises für das politische Buch 2005. Renner Institut. http:// www.renner-institut.at/download/texte/habermas 2006-03-09.pdf (accessed February 25, 2009).

Habermas, Jurgen. 2006b. Political Communication in Media Society: Does Democracy Still Enjoy an Epistemic Dimension? The Impact of Normative Theory on Empirical Research. Communication Theory 16(4): 411-26.

Hargittai, Eszter, Jason Gallo and Matthew Kane. 2008. Cross-Ideological Discussion among Conservative and Liberal Bloggers. Public Choice 134(1): 67-86.

Herring, S.C., I. Kouper, J.C. Paolillo, L.A. Scheidt, M. Tyworth, P. Welsch, E. Wright, and Ning Yu. 2005.

"Conversations in the Blogosphere: An Analysis "From the Bottom Up"." System Sciences, 2005. HICSS '05. Proceedings of the 38th Annual Hawaii International Conference.

Hetherington, Marc. 2001. Resurgent Mass Partisanship: The Role of Elite Polarization. American Political Science Review 95(3): 619-31.

Hindman, Matthew. 2008. The Myth of Digital Democracy. Princeton: Princeton University Press.

Hintz, Jerry L. and Ray D. Nelson. 1998. Violin Plots: A Box Plot-Density Trace Synergism. The American Statistician 52(2): 181-84.

Jacobson, Gary. 2007. "The War, the President, and the 2006 Midterm Congressional Elections." Paper presented at the Annual Meeting of the Midwest Political Science Association, Chicago.

Johnson, Thomas J. and Barbara K. Kaye. 2004. Wag the Blog: How Reliance on Traditional Media and the Internet Influence Credibility Perceptions of Weblogs among Blog Users. Journalism and Mass Communication Quarterly 81(3): 622-42.

Kastellec, Jonathan and Eduardo Leoni. 2007. Using Graphs Instead of Tables in Political Science. Perspectives on Politics 5(4): 755-71.
Knight, Jack and James Johnson. n.d. "Politics, Institutions, and Justification: A Pragmatist Theory of Democracy." unpublished manuscript.

Lodge, Milton and Charles S. Taber. 2007. "The Rationalizing Voter." Working paper.

Macedo et al. 2005. Democracy at Risk. Washington D.C.: Brookings Institution Press.

Malhotra, Neil and Jon A. Krosnick. 2007. The Effect of Survey Mode and Sampling on Inferences about Political Attitudes and Behavior: Comparing the 2000 and 2004 ANES to Internet Surveys with Nonprobability Samples. Political Analysis 15(3): 286-323.

McAdam, Doug, Sidney Tarrow and Charles Tilly. 2001. Dynamics of Contention. New York: Cambridge University Press.

McCarty, Nolan, Keith Poole, and Howard Rosenthal. 2006. Polarized America: The Dance of Ideology and Unequal Riches. Cambridge, MA: MIT Press.

McPherson, Miller, Lynn Smith-Lovin, and James M. Cook. 2001. Birds of a Feather: Homophily in Social Networks. Annual Review of Sociology 27: 415-44.

Meraz, Sharon. 2007. The Networked Political Blogsphere and Mass Media: Understanding How Agendas are Formed, Framed, and Transferred in the Emerging New Media Environment. Ph.D. Dissertation, The University of Texas at Austin.

Mutz, Diana. 2006. Hearing the Other Side: Deliberative versus Participatory Democracy. New York: Cambridge University Press.

Papachrissi, Zizi. 2002. The Virtual Sphere: The Internet as a Public Sphere. New Media and Society 4(1): 9-27.

Perlmutter, David D. 2008. Blogwars. New York: Oxford University Press.

Pole, Antoinette and Laura McKenna. 2007. "Blogging Alone? Political Participation and the Blogosphere." Working paper.

Polimetrix. 2005. "Polimetrix Validates Innovative Method of Online Sampling in California Special Election." Polimetrix. http://www.polimetrix.com/ news_110905.html (accessed 18 October 2007).

Poole, Keith, and Howard Rosenthal. 1997. Congress: A Political Economic History of Roll Call Voting. Oxford: Oxford University Press.

Prior, Markus. 2007. Post-Broadcast Democracy: How Media Choice Increases Inequality in Political Involvement and Polarizes Elections. New York: Cambridge University Press.

Putnam, Robert. 2000. Bowling Alone: The Collapse and Revival of American Community. New York: Simon \& Schuster.

Rivers, Douglas. 2006. "Sample Matching: Representative Sampling from Internet Panels.” Polimetrix White Paper Series. http://www.polimetrix.com/ documents/Polimetrix_Whitepaper_Sample_ Matching.pdf. 
Rosenblum, Nancy L. 2008. On the Side of the Angels: An Appreciation of Parties and Partisanship. Princeton NJ: Princeton University Press.

Rosenblum, Nancy L. 2009. "Responses on Political Theory, Idealism, and Extremism." Cato Unbound. http://www.cato-unbound.org/2009/02/11/nancyrosenblum/responses-on-political-theory-idealismand-extremism/.

Ruffini, Patrick. 2008. "Roots of Defeat." National Review Online, December 1. http://nrd.nationalreview. com/article/?q=MzY4ZDZkNzlhNGE2Y2EzOGQz ZTg3NTk3ODljYWVlZjA=.

Sanders, David, Harold D. Clarke, Marianne C. Stewart, and Paul Whiteley. 2007. Does Mode Matter for Modeling Political Choice? Evidence from the 2005 British Election Study. Political Analysis 15(3): 257-85.

Shirky, Clay. 2003. Powerlaws, Weblogs and Inequality. Clay Skirky's Writings About the Internet. http:// shirky.com/writings/powerlaw_weblog.html.

Sides, John, and Kimberly Gross. 2007. "Stereotypes of Muslims, Their Causes, and Their Consequences." Paper presented at the Annual Meeting of the American Political Science Association, Chicago.

Sinclair, Barbara. 2006. Party Wars: Polarization and the Politics of National Policy Making. Norman, OK: University of Oklahoma Press.

Skocpol, Theda. 2003. Diminished Democracy. Norman: University of Oklahoma Press.
Sunstein, Cass. 2008. Neither Hayek nor Habermas, Public Choice 134(1): 87-95.

Taber, Charles S., and Milton Lodge. 2006. Motivated Skepticism in Political Information Processing. American Journal of Political Science 50(3): 755-69.

Theriault, Sean. 2008. Party Polarization in Congress. New York: Cambridge University Press.

Thompson, Dennis F. 2008. Deliberative Democratic Theory and Empirical Political Science. Annual Review of Political Science 11: 497-520.

Vavreck, Lynn. 2007. The Exaggerated Effects of Advertising on Turnout: The Dangers of SelfReports. Quarterly Journal of Political Science 2(4): 297-305.

Wallsten, Kevin. 2007. Political Blogs: Transmission Belts, Soapboxes, Mobilizers, or Conversation Starters. Journal of Information Technology and Politics 4(3): 19-40.

Wojcieszak, Magdalena, and Diana Mutz. 2009. Online Groups and Political Discourse: Do Online Discussion Spaces Facilitate Exposure to Political Disagreement? Journal of Communication 59(1): 40-56.

Woodly, Deva. 2008. New Competencies in Democratic Communication? Blogs, Agenda-Setting, and Political Participation. Public Choice 134(1): 109-123.

Zaller, John. 1992. The Nature and Origins of Mass Opinion. New York: Cambridge University Press. 